\title{
Genomic variations associated with attenuation in Mycobacterium avium subsp. paratuberculosis vaccine strains
}

\author{
Tim J Bull ${ }^{1 *}$, Alex Schock ${ }^{2}$, J Michael Sharp², Mandisa Greene ${ }^{3,5}$, lain J McKendrick ${ }^{4}$, Jill Sales ${ }^{4}$, \\ Richard Linedale ${ }^{1}$ and Karen Stevenson ${ }^{3}$
}

\begin{abstract}
Background: Mycobacterium avium subspecies paratuberculosis (MAP) whole cell vaccines have been widely used tools in the control of Johne's disease in animals despite being unable to provide complete protection. Current vaccine strains derive from stocks created many decades ago; however their genotypes, underlying mechanisms and relative degree of their attenuation are largely unknown.

Results: Using mouse virulence studies we confirm that MAP vaccine strains $316 \mathrm{~F}$, II and 2e have diverse but clearly attenuated survival and persistence characteristics compared with wild type strains. Using a pan genomic microarray we characterise the genomic variations in a panel of vaccine strains sourced from stocks spanning over 40 years of maintenance. We describe multiple genomic variations specific for individual vaccine stocks in both deletion (26-32 Kbp) and tandem duplicated (11-40 Kbp) large variable genomic islands and insertion sequence copy numbers. We show individual differences suitable for diagnostic differentiation between vaccine and wild type genotypes and provide evidence for functionality of some of the deleted MAP-specific genes and their possible relation to attenuation.
\end{abstract}

Conclusions: This study shows how culture environments have influenced MAP genome diversity resulting in large tandem genomic duplications, deletions and transposable element activity. In combination with classical selective systematic subculture this has led to fixation of specific MAP genomic alterations in some vaccine strain lineages which link the resulting attenuated phenotypes with deficiencies in high reactive oxygen species handling.

Keywords: Mycobacterium avium subspecies paratuberculosis, Vaccine, Comparative genomics, Variable genomic island, Attenuation, Microarray

\section{Background}

Mycobacterium avium subspecies paratuberculosis (MAP) is a proven enteric pathogen with a wide host range that includes many domestic and wild animals [1]. It is the causal agent of Johne's disease (JD) in animals which is particularly common in countries with significant dairy industries leading to considerable economic losses [2]. MAP can infect, disseminate and persist in humans and has been suggested as a contributory factor in the development of Crohn's disease [3].

\footnotetext{
* Correspondence: tim.bull@sgul.ac.uk

'St. George's University of London Medical School, London SW17 ORE, UK Full list of author information is available at the end of the article
}

MAP vaccines are a major tool used in the control of JD in animals and can be highly profitable [4]. They have advantages over herd management [5] and culling strategies [6] in being more cost efficient, easier to implement on a wide scale and less reliant on diagnostic testing. It is clear however, that although able to prevent a majority of animals from reaching onset of clinical disease, their current formulations provide incomplete protection against infection and shedding [7-9], thus failing to eradicate the organism [10]. Most current whole cell vaccine preparations rely on subcultures of classic strains that were generated over 70 years ago [11] and some evidence suggests that, for killed preparations at least, more recently acquired local virulent strain types

\section{Biomed Central}


may be more effective [12]. Previous experience with BCG has shown that frequent in vitro passage of strains in different laboratories led to significant alterations in genomic profiles and diversities in attenuation and immunogenicity [13]. It is of importance therefore to derive accurate definitions of MAP vaccine genotypes to better standardize vaccine manufacture and understand the critical mechanisms determining vaccine attenuations and protective efficacies.

The distribution and worldwide use of MAP vaccines has continued since live 'attenuated' strains were selected in France (1924) and the UK (1940) using a method of sequential passage similar to that applied for the generation of BCG [14]. The degree and mechanism underlying their attenuation however is uncertain as virulence studies were not performed in any detail. Concerns in the 1980's regarding the use of live vaccine strains because of low shelf life and spread to the environment promoted the use of killed vaccine formulations. These were based on various combinations of three MAP strains comprising strain $2 \mathrm{e}$ from the UK, strain II from Canada and 316 F. A combination of these were used as live preparations for Norwegian goats in the 1960's and 1970's [15] and as a killed preparation delivered in mineral oil to Icelandic sheep in the 1950's [16]. Live vaccine formulations of $316 \mathrm{~F}$ alone were used in the 1960's and 70's in the UK [17] and Cyprus [18], 1980's in Hungary [19], 1990's in Germany [20] and Spain [21] and up until 2002 in New Zealand [22]. Killed preparations of $316 \mathrm{~F}$ alone have been used extensively worldwide [23] and are still available for commercial use. These strains, due to the difficulty in retaining mycobacteria in frozen seed stocks, have been maintained through regular subculture on a variety of laboratory in-house media. It is unsurprising therefore, that some reports suggest strain adaptation to growth in specialized media with loss of Mycobactin J dependence [24] and genome diversity [25] has occurred amongst some lineages.

In this work we demonstrate attenuation and differential virulence of vaccine strains $2 \mathrm{e}, \mathrm{II}$ and $316 \mathrm{~F}$ in a mouse model and use a full MAP genome microarray, supported by PCR and sequencing to investigate the genomic shifts of vaccine strains from a variety of lineages, including one recently resuscitated $316 \mathrm{~F}$ strain, originally lyophilised in 1966. We describe large genomic regions with deletions and tandem duplications uniquely associated with each vaccine clade, demonstrate the functionality of some of these deleted genes and hypothesise as to their role in virulence attenuation.

\section{Results}

Comparative Genomic Hybridisation of vaccine strains MAPAC hybridisations comparing each vaccine strain against a MAPK10 reference control were made (in duplicate) and averaged values displayed as scatterplots (Figure 1a and Figure 1b). Significant loss of signals in contiguous genes representative of large variable genomic island (vGI) deletions were identified in a 26.8 Kbp region of 316FNOR1960 (vGI-19: MAP3714MAP3735c; Table 1) and a $32.8 \mathrm{Kbp}$ region in both IIUK2000 and 2eUK2000 (vGI-20: MAP1694-MAP1727; Table 2). Two fold increases in signals were also seen in contiguous genes within a $24.9 \mathrm{Kbp}$ region of IIUK2000 (vGI-21: MAP2705c-MAP2733c; Table 3), a 40.7 Kbp region of 316 F-NLD1978 (vGI-22: MAP1750-MAP1789, Table 4) and a $11.0 \mathrm{Kbp} 316 \mathrm{FUK} 2000$ (vGI-1b: MAP0096c-MAP0104; Table 5).

Signal ratios from genes in multiple copies in the genome such as insertion elements are more difficult to interpret as changes in signal are related to copy number. Nevertheless IS900 signal ratios were significantly reduced in IIUK2000, 2eUK2000, 316FNOR1960, 316v, 316FUK2000 and elevated in 316FNLD1978 and 316FNLD2008. Increases in signals for IS1652-like elements were also seen in IIUK2000, 2eUK2000, 316FUK2000, 316FNLD1978 and 316FNLD2008 and decreases for this element in 316FNOR1960. IS256-like elements were more abundant in 2eUK2000 and also raised in 316v and 316FUK2000 but decreased in 316FNOR1960 relative to MAPK10. IS1311like elements were increased in $316 \mathrm{v}$ and decreased in 316FNOR1960. One of these elements (MAP0104) borders the previously described vGI-1b region which is bounded by short inverted repeat sequences and duplicated in MAP type III strains [26].

The tandem duplication vGI-21 was confirmed using primer set MAP2705.seq2 and MAP2733.R (Table 6) orientated to amplify only the end of one tandem repeat and the beginning of the other. This produced an amplicon of $651 \mathrm{bp}$ only with vaccine strain IIUK2000 and IIUK2001 (Additional File 1). Sequencing of this amplicon showed the duplication event to occur relative to the reference strain K10 genome (GenBank accession AE016958) at position 3066285 within the first copy of MAP2733c (truncated at aa251) followed by a unique region of $16 \mathrm{bp}$ (CCAGCTCGGCCACCCG) and then a second copy of MAP2704 (truncated at aa138) followed by the vGI-21 duplication thus comprising a tandem duplication of 24,971 bp spanning 29 ORFs (MAP2705cMAP2733c). PCR using primer pairs specific for this tandem duplication MAP2705.seq2 and MAP2733.R was negative for all other strains included in this study.

vGI-22 was confirmed as a tandem duplication using primer set MAP1789.F and MAP1750.R (Table 6) which produced an amplicon of 2967 bp with vaccine strain 316 F-NLD1978 only. Sequencing of this region showed the duplication event to comprise 40,744 bp spanning 41 ORFs (MAP1749-MAP1789). The duplication site occurs at Genbank accession AE016958 position 1952589 within 


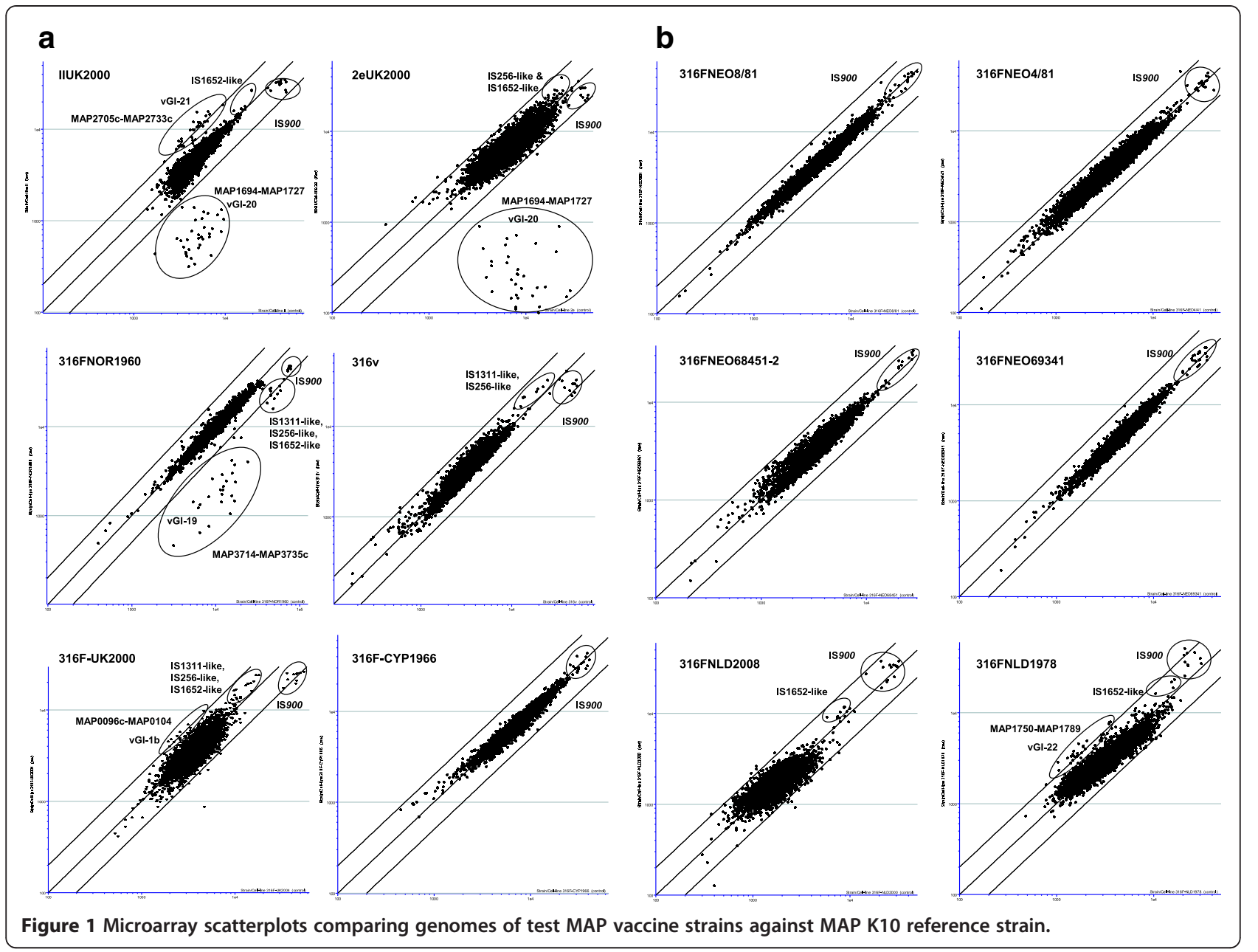

the first copy of MAP1790 (truncated at aa173) followed by an overlap region of $3 \mathrm{bp}$ (GGG) and then the second copy of MAP1748c (truncated at aa143) followed by the vGI-22 duplication. PCR with primer pairs specific for this tandem duplication (MAP1789.F, MAP1750.R) was negative for all other strains included in this study.

Several attempts to localise the vGI-1b duplication using outward facing primers around the region in a similar manner to vGI-21 and vGI-22 were unsuccessful and this region may not be present in 316UK2000 as a tandem duplication. qPCR was performed using both MAP0101 and MAP0103 specific primer pairs located inside vGI-1b and the relative copy number of each compared against a single copy genome target control represented by primer pairs to MAP2114c. Both MAP0101 and MAP0103 pairs showed a doubling of signal strengths relative to MAP2114c in strain 316FUK2000 whilst all other strains included in this study showed signal consistent with single copies of both these genes (Table 7).

\section{IS900 insertion site analysis}

To determine which IS900 sites were absent relative to the K10 reference genome, PCR primers were designed to specifically amplify each of the known 17 IS900 loci (Table 6). These were used to confirm the insertion of IS900 into each locus in the reference strain $\mathrm{K} 10$ and were also all positive in all $316 \mathrm{~F}$ strains and a caprine isolate CAM87. Both vaccine strains IIUK2000 and 2eUK2000 were missing IS900(MAP1722) whereas IS900(MAP1033) was also missing from vaccine strain 2eUK2000 but present in all other strains including vaccine strain IIUK2000. Comparative qPCR of IS900 copy number relative to MAP2114c, demonstrated a range of IS900 copies in vaccine strains that corresponded to the trend in hybridisation signals observed in MAPAC scatterplots (Figure 1a \& 1b). The ratio of copy number however was surprisingly higher than predicted, with vaccine strains IIUK2000 and 2eUK2000 having only 13 copies whilst MAPK10 and $316 \mathrm{~F}$ strains gave signals correspondent with 16-19 relative IS900 copy numbers (Table 7). 
Table 1 Deleted region (vGI-19) in 316FNOR1960

\begin{tabular}{|c|c|c|c|}
\hline Gene & Name & Putative function & Process \\
\hline MAP3714 & fadD2 & LuxE like Acyl-coA synthase & Fatty Acid Metabolism \\
\hline MAP3715 & & Unknown & \\
\hline MAP3716c & fadE6 & Acyl-CoA dehydrogenase & Fatty Acid Metabolism \\
\hline MAP3717c & & Dipeptidyl aminopeptidase & \\
\hline MAP3718c & & Transcriptional regulator & \\
\hline MAP3719 & & Glyoxalase & Anti-host killing factor \\
\hline MAP3720 & & Unknown & \\
\hline${ }^{*}$ MAP3721 & & polyketide synthase associated protein PapA2 & Cell Adhesion \\
\hline *MAP3722 & & Unknown & \\
\hline *MAP3723C & & Transcriptional regulator & \\
\hline *MAP3724 & & Unknown & \\
\hline${ }^{*}$ MAP3725 & & PPE-1 & Signalling \\
\hline${ }^{*}$ MAP3726 & fepD & ABC-type cobalamin/Fe3+ siderophore transporter & Transporter \\
\hline${ }^{*}$ MAP3727 & fepC & ABC-type cobalamin/Fe3+-siderophore transporter & Transporter \\
\hline${ }^{*}$ MAP3728 & fepB & ABC-type cobalamin/Fe3+-siderophore transporter & Transporter \\
\hline *MAP3729 & taud & Taurine catabolism dioxygenase & Taurine resistance \\
\hline *MAP3730 & tehB & O-methyltransferase & Tellurite resistance \\
\hline *MAP3731c & & $A B C$ non-ribosomal derived peptide transporter & Transporter \\
\hline${ }^{*}$ MAP3732C & & $A B C$ non-ribosomal derived peptide transporter & Transporter \\
\hline${ }^{*}$ MAP3733C & & $A B C$ non-ribosomal derived peptide transporter & Transporter \\
\hline${ }^{*}$ MAP3734C & & ABC non-ribosomal derived peptide transporter & Transporter \\
\hline${ }^{*}$ MAP3735c & & $A B C$ non-ribosomal derived peptide transporter & Transporter \\
\hline
\end{tabular}

* $=$ MAP specific genes.

\section{Functional analysis of tellurite resistance}

One MAP specific gene predicted to be deleted in vGI19 was MAP3730 (Table 1), a S-adenosylmethionine -dependent methyltransferase with homologues to tellurite resistance genes (tehB) involved in bacterial virulence and persistence $[27,28]$. The functionality of this gene in mycobacteria has not previously been investigated. Using a solid culture plate assay we compared tellurite resistance (MIC) of MAP strains with and without the vGI-19 deletion (Table 7). This demonstrated a wide MIC range $(8->512 \mu \mathrm{g} / \mathrm{ml})$ between strains, with significant reductions associated with vGI-19 (316FNOR1960) deletion over full genome complement strains. Of note however was the very low level of tellurite resistance $(8 \mu \mathrm{g} /$ $\mathrm{ml}$ ) found in strains containing the vGI-20 (IIUK2000 \& 2eUK2000) deletion.

\section{Assessment of virulence using a mouse model}

The virulence of vaccine strains 316FUK2001, IIUK2001 and 2eUK2001 was compared with wild type strain JD87/107 in a mouse model. Ten mice from each of five groups (four inoculated with the different MAP strains and a negative control group inoculated with $\mathrm{PBS}$ ) were killed at 4, 8 and 12 weeks post inoculation. Body, spleen and liver weights were recorded. Samples of the liver were taken for bacteriological culture and histopathology. Mean bodyweights increased with age, but no statistically significant difference was observed in mean body weight between any of the vaccine strains and the control wild type strain at any of the time points $(p=0.11)$. There was strong evidence of a difference in pattern over time between the mean rank spleen weight expressed as a percentage of body weight of the mice inoculated with the different MAP strains relative to those receiving PBS, where those inoculated with MAP had increasingly higher mean rank percentage weights $(\mathrm{P}=0.006)$. Differences between the MAP strains were not formally statistically significant $(\mathrm{p}=0.06)$ although the control virulent strain JD87/107 showed an increase in mean rank spleen weight percentage between weeks 4 and 8, and 316FUK2001 had an increase between weeks 8 and 12. There was no statistical evidence for differences in the mean levels of liver weight expressed as a percentage of body weight either for different strains or over time for any of the MAP strains $(p=0.2)$. However, there was some evidence of a difference between the means for the MAP strains and the lower mean weights associated with PBS ( $\mathrm{p}=0.018)$. 
Table 2 Deleted region (vGI-20) in vaccine strains IIUK2000 and 2eUK2000

\begin{tabular}{|c|c|c|c|}
\hline Gene & Name & Putative function & Process \\
\hline MAP1694 & papA2 & Polyketide synthase & Cell Adhesion \\
\hline MAP1695c & & Transcriptional regulator & \\
\hline MAP1696c & hsp18_1 & Heat Shock Protein & Stress protein \\
\hline MAP1697 & & Transcriptional regulator & \\
\hline MAP1698c & hsp18_2 & Heat Shock Protein & Stress protein \\
\hline MAP1699 & thil & Thiamine biosynthesis & \\
\hline MAP1700c & & $\beta$-lactamase & \\
\hline MAP1701c & & Biotin carboxylase subunit & \\
\hline MAP1702C & & Thioredoxin & \\
\hline MAP1703C & & Unknown & \\
\hline MAP1704c & & Glyoxalase & Anti-host killing factor \\
\hline MAP1705c & & Transcriptional regulator & \\
\hline MAP1706 & & Chitinase-like protein & \\
\hline MAP1707 & & 3-ketoacyl-(acp) reductase & Fatty Acid Metabolism \\
\hline MAP1708 & & Phosphohydrolase-like protein & \\
\hline MAP1709 & fadD11_2 & LuxE like Acyl-protein synthetase & Fatty Acid Metabolism \\
\hline MAP1710 & & 3-oxoadipate enol-lactonase & Fatty Acid Metabolism \\
\hline MAP1711c & & Transcriptional regulator & \\
\hline MAP1712 & & CoA-transferase family III & \\
\hline MAP1713 & fadDE20_1 & Acyl-CoA dehydrogenase & Fatty Acid Metabolism \\
\hline MAP1714 & fadA_2 & Acyl-CoA dehydrogenase & Fatty Acid Metabolism \\
\hline MAP1715 & fadB_2 & Acyl-CoA dehydrogenase & Fatty Acid Metabolism \\
\hline MAP1716 & & Short chain dehydrogenase & Fatty Acid Metabolism \\
\hline MAP1717 & & Unknown & \\
\hline *MAP1718c & & Low identity to MTB immunogen MPT63 & Cell internalization factor \\
\hline *MAP1719c & & Transcriptional regulator & \\
\hline *MAP1720 & & Nucleoside-diphosphate-sugar epimerases & Cell envelope biosynthesis \\
\hline${ }^{*} \mathrm{MAP} 1721 \mathrm{C}$ & & Transcriptional regulator & \\
\hline *MAP1722 & & 15900 & \\
\hline *MAP1723 & & NADP oxidoreductase coenzyme F420-dependent & \\
\hline *MAP1724C & & Cytochrome b N & \\
\hline *MAP1725c & & Catalase & Anti-host killing factor \\
\hline *MAP1726c & & Transcriptional regulator & \\
\hline *MAP1727 & & Esterase_lipase & Fatty Acid Metabolism \\
\hline
\end{tabular}

* $=$ MAP specific genes.

MAP was recovered from the liver tissue of mice four weeks post inoculation in all groups except the control group inoculated with PBS. By 12 weeks post infection, MAP was recovered from the tissues of only one mouse inoculated with vaccine strain 2eUK2001 (mean count $46 \mathrm{cfu} / \mathrm{g}$ ), from 6 mice inoculated with IIUK2001 (mean counts between 46 and $315 \mathrm{cfu} / \mathrm{g}$ ) and from all the mice inoculated with the virulent JD87/107 strain (mean counts 1.4-7 $\times 10^{6} \mathrm{cfu} / \mathrm{g}$ ) suggesting attenuation of each of the vaccine strains (Figure 2a). Mean rank counts increase over time for the JD87/107 strain, while dropping for all the other MAP strains, this being most rapid for the 2eUK2001 strain but ultimately most notable for strain 316FUK2001. Statistical assessment of the effect of the strain by time interaction on the mean rank count indicate that differences exist in the abilities of the MAP vaccine strains to survive or persist in mice $(\mathrm{p}=0.02)$.

Infections of the liver result in multifocal hepatitis characterised by clusters of inflammatory cells. To measure the effect of the experimental infection with MAP, 
Table 3 Tandem duplicated region (vGI-21) in vaccine strain IIUK2000

\begin{tabular}{|c|c|c|c|}
\hline Gene & Name & Putative function & Process \\
\hline MAP2705c & & Ketosteroid isomerase & \\
\hline MAP2706c & & $\mathrm{N}$-acylglucosamine 2-epimerase like & \\
\hline MAP2707c & & Signal protein & \\
\hline MAP2708c & & Glutamine amido transferase & Amino acid-Lipid biosynthesis \\
\hline MAP2709c & tesB2 & Acyl-CoA thioesterase II & Amino acid-Lipid biosynthesis \\
\hline MAP2710c & $\mathrm{pdxS}$ & Pyridoxal 5'-phosphate synthase & Amino acid-Lipid biosynthesis \\
\hline MAP2711c & & Nudix Hydrolase 26 & \\
\hline MAP2712C & & Phosphatidylinositol alpha-mannosyltransferase & \\
\hline MAP2713c & & Lauroyl acyltransferase & Lipid biosynthesis \\
\hline MAP2714c & pgsA & CDP-alcohol phosphatidyltransferase & Lipid biosynthesis \\
\hline MAP2715c & & Diadenosine tetraphosphate & \\
\hline MAP2716c & thrs & threonyl-tRNA synthetase & \\
\hline MAP2717 & & $\mathrm{Na}+/ \mathrm{H}+$ antiporter & \\
\hline MAP2718c & & N-alpha-acyl-glutamine aminoacylase & Amino acid biosynthesis \\
\hline MAP2719c & & Acyl-CoA thioesterase & Amino acid biosynthesis \\
\hline MAP2720c & & Aldo-keto reductase & \\
\hline MAP2721 & & Unknown & \\
\hline MAP2722C & & 2-Nitropropane dioxygenase & \\
\hline MAP2723c & & Unknown & \\
\hline MAP2724C & & Unknown & \\
\hline MAP2725c & & Transcriptional regulator & \\
\hline MAP2726c & $\mathrm{fdxA}$ & Ferredoxin & Fe scavenging \\
\hline MAP2727 & & S-adenosylmethionine-dependent methyltransferase & \\
\hline MAP2728 & & Transcriptional regulator & \\
\hline MAP2929c & pcaB & Lyase I like & Benzoate metabolism \\
\hline MAP2730c & pcaG & Protocatechuate 3,4-dioxygenase & Benzoate metabolism \\
\hline MAP2731c & pcaH & Protocatechuate 3,4-dioxygenase & Benzoate metabolism \\
\hline MAP2732C & & Hemerythrin oxygen binding like protein & \\
\hline MAP2733C & & Rieske (2Fe-2S) protein & \\
\hline
\end{tabular}

the densities of mononuclear leucocyte clusters were counted. Small numbers of leucocyte clusters $(<0.22$ clusters per field) were observed in liver samples from mice inoculated with PBS, though no acid fast bacilli (AFB) were detected in any of these samples. Large differences in the mean ranked density of leucocyte clusters between strains were identified $(\mathrm{p}<0.001)$ with the wild type strain JD87/107 having the highest mean ranked densities of clusters (Figure 2b). Strain 2eUK2001 showed evidence of higher mean rank densities than the 316FUK2001 and IIUK2001 strains ( $\mathrm{p}=0.03)$. The ranked density of leucocyte clusters with AFB showed highly statistically significant differences between the means of MAP strains $(\mathrm{p}<0.001)$, with the JD87/107 strain consistently showing higher mean densities, with this effect being more pronounced from 8 weeks post infection (Figure 2c). The vaccine strains all tended to exhibit increasingly lower mean ranked densities over the lifetime of the experiment $(\mathrm{p}=0.002)$, with consistent patterns of differences between strains $(p=0.008)$ : strain IIUK2001 showed the largest mean rank densities, strain 316FUK2001 the lowest, with 2eUK2001 intermediate. The histopathology results show that all strains elicited a similar inflammation at 4 weeks. Only thereafter some differences between the inflammatory responses to the strains became apparent. In addition, the analysis of mean bacterial counts and AFB positive clusters showed the reduced ability of the vaccine strains to survive and persist within mice. Overall, these results provide proof of attenuation of the vaccine strains with respect to a wild type MAP strain.

\section{Discussion}

In this study, we examined genomic and phenotypic characteristics of a panel of MAP vaccine strains obtained 
Table 4 Tandem duplicated region (vGI-22) present in vaccine strain 316FNLD1978

\begin{tabular}{|c|c|c|c|}
\hline Gene & Name & Putative function & Process \\
\hline MAP1750 & & Unknown & \\
\hline MAP1751 & wcaG & NAD-dependant epimerase/dehydratase & Cell envelope biosynthesis \\
\hline MAP1752C & & Aldo-keto reductase & \\
\hline MAP1753 & & Acyltransferase & \\
\hline MAP1754C & uspA & Adenine nucleotide alpha hydrolase & Stress Protein \\
\hline MAP1755c & nirC & Formate/nitrite transporter & \\
\hline MAP1756C & rshA & Anti-sigma factor & \\
\hline MAP1757c & & Sigma-70 factor & \\
\hline MAP1758C & nrtC & Acyl-CoA dehydrogenase & \\
\hline MAP1759c & osmC & Osmotic shock-like protein & \\
\hline MAP1760c & & tat translocated iron dependent peroxidise & \\
\hline MAP1761c & & Peptidase like lipoprotein & \\
\hline MAP1762C & & FTR1; high affinity iron transporter & \\
\hline MAP1763c & & Unknown & \\
\hline MAP1764 & & Unknown & \\
\hline MAP1765c & rssA & Patatin like esterase & Fatty acid Metabolism \\
\hline MAP1766C & & Cellobiose $\mathrm{ABC}$ transporter & \\
\hline MAP1767c & & $\mathrm{ABC}$ transporter & \\
\hline MAP1768C & & $\mathrm{ABC}$ transporter & \\
\hline MAP1769c & & Transcriptional regulator & \\
\hline MAP1770c & & Sigma-70 factor & \\
\hline MAP1771c & & 15900 & \\
\hline MAP1772 & & Unknown & \\
\hline MAP1773c & & Nuclear transport factor 2 & Steroid metabolism \\
\hline MAP1774C & pncA & Isochorismatase & Nicotinamide metabolism \\
\hline MAP1775 & doxX & Unknown & \\
\hline MAP1776c & & Nucleotide phosphokinase-like & \\
\hline MAP1777c & & Unknown & \\
\hline MAP1778c & aroK & Shikimate kinase & \\
\hline MAP1779c & & Phosphotransferase & \\
\hline MAP1780c & lipT & Esterase_lipase & Fatty acid Metabolism \\
\hline MAP1781 & |ppl & Lipoprotein & \\
\hline MAP1782C & & p450 cytochrome & \\
\hline MAP1783 & & Transcriptional regulator & \\
\hline MAP1784C & & Lipoprotein & \\
\hline MAP1785 & & 15900 & \\
\hline MAP1786C & & Dihydropicolinate reductase-like & \\
\hline MAP1787c & & Short chain dehydrogenase & \\
\hline MAP1788 & & Transcriptional regulator & \\
\hline MAP1789 & & Unknown & \\
\hline
\end{tabular}


Table 5 Duplicated region (vGI-1b) in vaccine strain 316FUK2000

\begin{tabular}{llll}
\hline Gene & Name & Putative function & Process \\
\hline MAP0095C & nuol_1 & NADH dehydrogenase subunit I & Fatty acid metabolism \\
MAP0096C & & Membrane fatty acid desaturase & Fatty acid metabolism \\
MAP0097c & & Membrane fatty acid desaturase & expression regulator \\
MAP0098C & Transcription regulator & stress response \\
MAP0099 & gcs2 & Stress protein & glutathione biosynthesis \\
MAP0100 & gcs2 & Glutamate-cysteine ligase & glutathione biosynthesis \\
MAP0101 & & Glutamate-cysteine ligase & \\
MAP0102 & & Unknown & DNA mutator transposon \\
MAP0103C & Unknown & Transposase & \\
MAP0104 & IS1311 &
\end{tabular}

from several laboratories around the world including both low and high passage examples of the $316 \mathrm{~F}$ lineage. Using a mouse model, we assessed the virulence ofrepresentative clades of three vaccine strains (2e, II, 316 F) with respect to a virulent MAP clinical isolate. The vaccine strains were clearly attenuated with regard to their ability to survive and persist in the mice as evidenced from the reduced numbers of MAP recovered and reduced numbers of leucocyte clusters containing AFB in the livers. This supports previous studies showing decreased persistence of the same $316 \mathrm{~F}$ and $2 \mathrm{e}$ strains in calves after 8 months [29] and illustrates the utility of the C57BL/6 mouse model for virulence studies.

Using a pan-genomic $\mathrm{MAP} / \mathrm{MAH}$ microarray we demonstrated that the genomes of all but one of the $316 \mathrm{~F}$ strains in the test panel contain the same full genome complement as the reference virulent bovine MAP type II strain MAPK10. One $316 \mathrm{~F}$ strain obtained from Norway (316FNOR1960) contained a single deleted region (vGI-19) spanning 21 ORF's (including $10 \mathrm{MAP}$ specific genes). Two strains not of the $316 \mathrm{~F}$ lineage (2eUK2000 and IIUK2000) contained a different deleted region (vGI-20), identical in both strains, spanning 34 ORF's (including 10 MAP specific genes). Specific PCR for MAP1723 (Table 6), located within the vGI-20, on 2eUK2001 and IIUK2001 were negative confirming that the vGI-20 region was not present in these strains (Additional File 1). The inclusion of MAP-specific genes in these deleted regions is an important observation as these genes could provide the basis for differentiating infected from vaccinated animals (DIVA). Indeed, the deleted region vGI-19 contains part of the $38 \mathrm{~kb}$ pathogenicity island described by Stratmann et al. (2004) [30] which contains genes encoding a number of antigens with diagnostic potential [31]. Both deleted regions vGI-19 and vGI-20 contain genes potentially involved in virulence and pathogenesis (Table 1) and their deletion could therefore have a profound effect on the virulence of these strains. In this study we demonstrated using a mouse model that both vaccine strains $2 \mathrm{eUK} 2001$ and IIUK2001 were attenuated with respect to a wild type MAP strain. In addition, vaccine strain IIUK2000 and IIUK2001 were found to contain a large 41 ORF tandem duplication (vGI-21) which includes copies of benzoate and lipid metabolic pathways. Vaccine strain 2eUK2000 comes from the same stock as 2eUK2001 and was maintained at the VLA, UK for over 50 years on a mineral deficient medium (Watson Reid 'A' block) whilst vaccine strain IIUK2000 was not. We suggest that the vGI-21 duplication in vaccine strain IIUK2000 was selected by these differences in media and fixed into the genome to compensate in vitro for the deletion of lipid biosynthesis and carbon usage repertoires, removed by the vGI-20 deletion.

The large deletion vGI-19 present in vaccine strain 316FNOR1960 was not present in any of the other 316 $\mathrm{F}$ strains including an early low passage lineage (316FCYP1966) and a more recent isolate (316 F2001) shown to be significantly attenuated in our virulence studies. Notably, part of vGI-19 is also present in the same gene order within the related MAH104 genome (GenBank reference CP000479). Together these suggest that any ancestral precursor and therefore the original $316 \mathrm{~F}$ strain would be unlikely to be missing vGI-19. We hypothesise that the vGI-19 deletion appeared in the 316 FNOR1960 strain some point after its acquisition and transfer to Norway in 1960 from the VLA, UK. This strain is recorded as having been maintained, uniquely on Dubos medium with added pyruvate [15] and we hypothesise that this medium was at some point selective. This is supported by the vGI-19 deletion in this strain including gene homologues of glyoxylate enzymes associated with pyruvate metabolism [32]. This strain previously has been used successfully as a live vaccine suggesting that it is attenuated. The knockout of the glyoxylate shunt could significantly affect the strain's ability to control anaerobic respiration [33] and intracellular persistence [34], which may indicate that attenuation in 
Table 6 PCR primer sets used in this study

\begin{tabular}{ll}
\hline Gene set & Sequence \\
\hline vGl-1b: (internal gene primer sets) & \\
MAP0101.F & GGTACCGACTTGGTCCAGA \\
MAP0101.R & CCCGTCAGATCCATTACGAC \\
MAP0103.F2 & GAGCGCCAACCTATCTCAAC \\
MAP0103.R & TGGTTTGGAGATCCCTGAAG \\
VGl-19 (internal gene primer set) & \\
MAP3733c.F & TTCATGTTGTCCTCACCCG \\
MAP3733C.R & CATCGCGAGCGTAGCCGCTG \\
vGI-20 (internal gene primer set) & \\
MAP1723.F & GGAGTATGGAACCATCGCTG \\
MAP1723.R & TGATGTAACGGGCGTGCAAG \\
VGI-21 (specific for tandem duplicated region in IIUK2000/1) \\
MAP2705.SEQ2 \\
MAP2733.R & CGATGAAGGCCTACTGGTC \\
TCAACTGGCTCCTCCTTTG
\end{tabular}

VGI-22 (specific for tandem duplicated region in 316FNLD1978)

MAP1789.F

TTTGGCACTACAACGAGCTG

MAP1750.R

GATCGAGAAGAGGGGAGTCA

MAP2114C (single copy gene for control PCR)

MAP2114C.F

MAP2114C.R

TGGAAGCTACCCAAATCACC

15900

$\mathrm{AV}-1$

AV-2

pre16SrRNA

pre16SrRNA.R

pre16SrRNA.F

Tellurite (tehB)

MAP3730.F

MAP3730.R

MIRU3 (MAP3981-2)

MIRU3.F

MIRU3.R

IS900(MAP0034)

MAP0033C.F

MAP0035.R

IS900(MAP0159C)

MAP0158.F

MAP0160.R

IS900(MAP0967)

MAP0966C-MAP0967.F

MAP0967-MAP0968.R

IS900(MAP1033)

MAP1032C.F

MAP1034c.R
GAGAAGTAGGCCGCGTAGTC

ATGTGGTTGCTGTGTTGGATGG

CCGCCGCAATCAACTCCAG

GCGCAGCGAGGTGAATTT

TTTGGCCATACCTAGCACTCC

GGTITGACGACAGAGATGCG

GGCATGGTGTACGACAAGGA

ACATTCACCCTGTCCATTCC

CCTCCTTACGGAGCAGGAA

AGCTGCCGGGAGTTGATCT

TCACGGCTCACCGCACGCT

CCCGTGACAAGGCCGAAGA

CGTITGCACCTCGATGGCC

CGTGACGAACGACATGTGTT

GTAGAACCCGACCAGCAGC

GACCTGGCACCTGTATCCC
GCTCGAGACATTTAGCCCAC
Table 6 PCR primer sets used in this study (Continued)

\begin{tabular}{|c|c|}
\hline \multicolumn{2}{|l|}{ IS900(MAP1722) } \\
\hline MAP1720-MAP1721C.F & CTAAGGTGGCCAGCGTITCT \\
\hline MAP1723.R & GGTTGGAGACAACCTCGTTC \\
\hline \multicolumn{2}{|l|}{ IS900(MAP1771C) } \\
\hline MAP1770c.F & ACAATTCGGCGATCGTCTCG \\
\hline MAP1772.R & CGCGGACAGACACAGGTAGG \\
\hline \multicolumn{2}{|l|}{ IS900(MAP1785) } \\
\hline MAP1784c.F & GTCGACCATCGCTCTTCCCT \\
\hline MAP1786c.R & ATCGGTGTCGAGGACATTCC \\
\hline \multicolumn{2}{|l|}{ IS900(MAP1793C) } \\
\hline MAP1792.F & CAATGGATGGTCGTCACCTG \\
\hline MAP1794.R & CGGCCCGCTTGATCCATTTG \\
\hline \multicolumn{2}{|l|}{ IS900(MAP2034C) } \\
\hline MAP2033-MAP2034C.F & CCGCAAGTAGTGCACTATGG \\
\hline MAP2035.R & TATTCGGGGTTGTTCAGGGA \\
\hline \multicolumn{2}{|l|}{ IS900(MAP2108) } \\
\hline MAP2105.F & CAGGCACGGAACACAGTTCG \\
\hline MAP2109c.R & TGTTCGGCTACGGCATACTG \\
\hline \multicolumn{2}{|l|}{ IS900(MAP2157) } \\
\hline MAP2156.F & CTGCAAACACAGCCCAATC \\
\hline MAP2158.R & CAACTTCGGCAAGTTCACC \\
\hline \multicolumn{2}{|l|}{ IS900(MAP2203c) } \\
\hline MAP2202c.F & TCCCGGTAGAAGATCATGTG \\
\hline MAP2204c.R & GACAATCTGCCGTCGTATCA \\
\hline \multicolumn{2}{|l|}{ IS900(MAP2444C) } \\
\hline MAP2443.F & AACCTTGACCCACACCTTCC \\
\hline MAP2445.R & TGAGCTCGCCGGCGAAATA \\
\hline \multicolumn{2}{|l|}{ IS900(MAP2577) } \\
\hline MAP2567c.F & CGTTCTGGGCATCCATCGACG \\
\hline MAP2578.R & TCACGGCGGTCAGGTTACTTC \\
\hline \multicolumn{2}{|l|}{ IS900(MAP3480) } \\
\hline MAP3479c.F & GTTGAACTITCCGACCAACC \\
\hline MAP3480-3481.R & GGTTAGCGGGAGAAAAGCTC \\
\hline \multicolumn{2}{|l|}{ IS900(MAP4066) } \\
\hline MAP4065.F & TGGGCCTGAGGTCAGAACCA \\
\hline MAP4067c.R & GAAGACCACCTCTACCTCAC \\
\hline \multicolumn{2}{|l|}{ IS900(MAP4281) } \\
\hline MAP4280.F & GCTGACCGAGAAGGGCTAC \\
\hline MAP4282.R & CGTAAGTGACTGGCTCATGG \\
\hline
\end{tabular}

MAP gene annotation corresponds to GenBank AE016958.

this strain may be related to this loss. A 2002 isolate of this strain was shown to be highly immunogenic in goats [35] and forms part of a $316 \mathrm{~F} / 2 \mathrm{e}$ live commercial vaccine product (Paratuberkulose-vaksine, National Veterinaria Institute, Oslo, Norway) however there is no evidence that 
Table 7 MIRU, vGI, Tellurite MIC and IS900 / MAP0101 / MAP0103 genome copy numbers

\begin{tabular}{|c|c|c|c|c|c|}
\hline \multirow[t]{2}{*}{ Strain } & \multirow{2}{*}{$\begin{array}{c}\text { MIRU3 } \\
\text { bp (copy no) }\end{array}$} & \multirow[t]{2}{*}{ vGls* } & \multirow{2}{*}{$\begin{array}{c}\text { Tellurite MIC } \\
\mu \mathrm{g} / \mathrm{ml}\end{array}$} & \multicolumn{2}{|c|}{ Copy number relative to MAP2114c } \\
\hline & & & & IS900 & MAP0101/ MAP0103 \\
\hline $316 F N L D 2008$ & $244(1)$ & & 128 & 17 & 1 \\
\hline 316FUK2001 & $244(1)$ & & nd & nd & nd \\
\hline 316FNLD1978 & $244(1)$ & $22^{\mathrm{dp}}$ & 128 & 19 & 1 \\
\hline $316 F U K 2000$ & $297(3)$ & $1 b^{d p}$ & 128 & 16 & 2 \\
\hline 316FNEO4/81 & $297(3)$ & & nd & 17 & 1 \\
\hline 316FNEO8/81 & $297(3)$ & & nd & 17 & 1 \\
\hline 316FNEO68451-2 & $297(3)$ & & nd & 17 & 1 \\
\hline $316 F N E O 69341$ & $297(3)$ & & nd & 17 & 1 \\
\hline $316 \mathrm{~V}$ & $297(3)$ & & nd & 16 & 1 \\
\hline 316FCYP1966 & $297(3)$ & & $>512$ & 16 & 1 \\
\hline 316 FNOR1960 & $297(3)$ & $19^{\mathrm{dl}}$ & 64 & 16 & 1 \\
\hline IIUK2000 & $297(3)$ & $20^{\mathrm{dl}} \& 21^{\mathrm{dp}}$ & 8 & 13 & 1 \\
\hline 2eUK2000 & $297(3)$ & $20^{\mathrm{dl}}$ & 8 & 13 & 1 \\
\hline MAPK10 & 297 (3) & & 128 & 17 & 1 \\
\hline CAM87 & $297(3)$ & & 256 & 17 & 1 \\
\hline
\end{tabular}

nd = not done.

* vGl status for vGl-1b, vGl-19 - vGl-22 either duplicated (dp) or deleted (dl), else no entry designates present as a single copy region.

vGI-19 was deleted when the strain was used, albeit very effectively, on goats in the 1960-70's [15].

We tested the potential impact provided by deletion of the putative tellurite resistance gene (tehB) included in vGI-19 on 316FNOR1960 phenotype. Tellurite is highly toxic to bacteria due to its action on DNA synthesis. It is an important mechanism by which animals combat intracellular microorganisms [27] and was used in early studies as a tuberculosis/leprosy therapeutic [36]. Bacterial resistance to tellurite is inducible, is associated with virulence [28] and is linked to catalases which are required to process the superoxide anions generated as a result of bacterial metabolic mechanisms used to inactivate tellurite. We show a significantly increased sensitivity to tellurite in 316FNOR1960 whilst other $316 \mathrm{~F}$ strains either matched or exceeded the resistance of the two wildtype strains tested (K10:bovine, CAM87:caprine). Interestingly the strains most sensitive to tellurite were IIUK2000 and 2eUK2000 which lack the tehB gene. The metabolism of tellurite generates high reactive oxygen species which subsequently need to be de-toxified by catalase [37]. Significantly the vGI-20 deletion in these strains includes loss of the catalase gene homologue MAP1725c. Both vaccine deletion regions thus involve alterations in metabolic pathways associated with deactivation of high reactive oxygen species toxicity, which suggests this may be an important mechanism underlying attenuation in these strains.

Several of the other vaccine strains tested are also reported to have been maintained on markedly different media which may have similarly promoted or selected for genomic and phenotypic diversities. 316FNLD1978, available as a heat killed vaccination for dairy cattle since 1985 [38], was found to contain a large tandem duplication (vGI-22) unique to this strain. It is notable that this isolate was selectively subcultured on potato starch medium to enhance its growth (P. Willemsen personal communication) and now grows with difficulty on other media. It is tempting to speculate that the acquisition of extra copies of 14 ORFs including cell wall, fatty acid biosynthesis genes and two extra copies of IS900 are a direct result of the selective process performed on this strain.

We demonstrated in this study that vaccine strain 316FUK2001 was clearly attenuated with respect to wild type MAP strain JD87/107. The vGI-19 deletion found in 316FNOR1960 and the vGI-20 deletion found in 2eUK2000 and IIUK2000 were not detected by PCR in this strain suggesting that attenuation in this strain is due to different genetic polymorphisms. A duplicated region (vGI1b) was detected in vaccine strain 316FUK2000, which may possibly have arisen as an adaptation to growth on liquid Watson Reid media.

Insertion sequences bordering specific genomic regions have previously been associated with variably tandem duplicated [39] and possibly large genomic inversions [40] and contribute highly to the degree of plasticity in the MAP genome. Variations in copy number of insertion elements including IS900, IS1311, IS256 and IS1652-like elements were seen between vaccine strains and virulent isolates. An IS1311 was found immediately bordering the vGI-1b region duplicated in 316 F-UK2000 but not other 316 F strains. Similar genomic variations including vGI-1b 


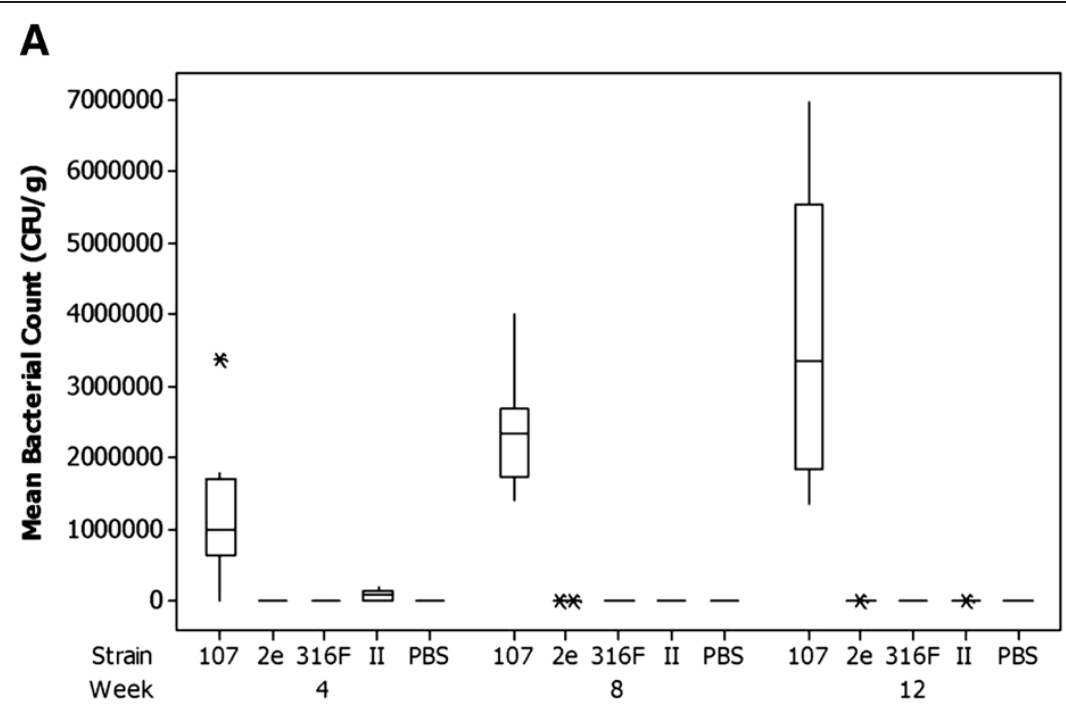

B

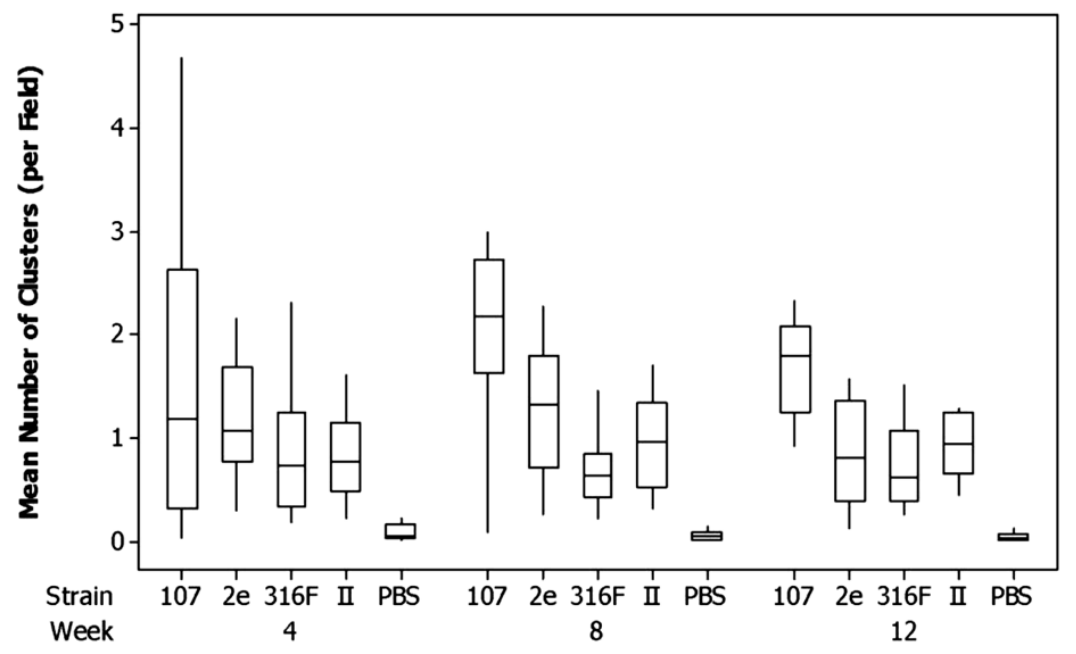

C

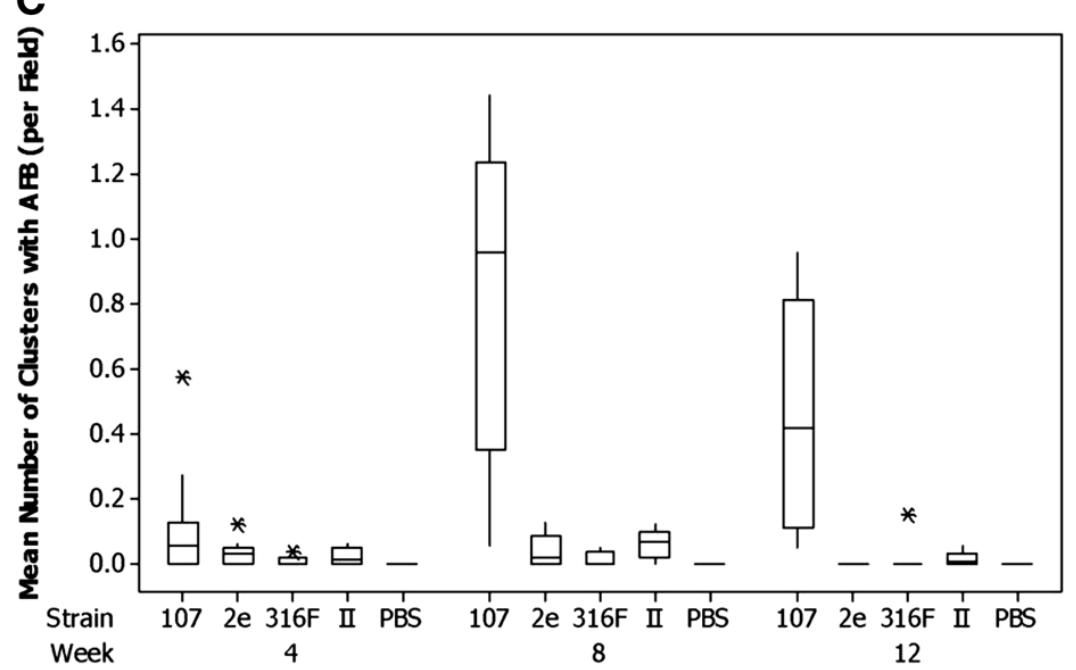

Figure 2 (See legend on next page.) 
have been observed in virulent MAP strains [26]. IS900, a definitive element of MAP found in all clinical and vaccine strains, was also shown to be present in a variety of copy numbers. This work used comparative ratios of qPCR signals to estimate the average number of IS900 copies per cell per culture relative to two single copy MAP genes using an assumption determined from a MAP assembled genome sequence that MAPK10 would contain 17 copies. Our results confirm previous studies showing the vaccine strain 316v used in Australia for ELISA testing [41] contains one less genomic copy of IS900 [42] than most other 316 F strains [25]. Vaccine strain 316FNLD1978 exhibited higher gene signal ratios consistent with the two extra copies of IS900 copies inside the duplication of vGI22. Vaccine strains IIUK2000 and 2eUK2000 contained lower signal ratios consistent with loss of an IS900 copy inside the deletion region vGI-20. Consistently however the calculated IS900 copy number in these strains was much lower than expected using the ratio method. Using site specific PCR we confirmed 16 IS900 filled insertion sites in the genomes of these strains whereas the ratio method, using MAPK10 as a standard, predicted only 13 copies. The reason could be technical, perhaps involving incomplete bacterial lysis of these unusual strains, however IS900 is known to replicate in episomal minicircles [43] and when all consensus insertion sites are filled they may exist as extra genomic components awaiting transposition. If this is indeed the case, virulent MAP strains would have the capacity to contain more than the predicted 17 IS900 copies per cell. This could be an important factor in studies relying on qPCR to determine accurate estimates of MAP load [44].

MIRU3 is a short tandem repeat sequence located within the sensX3-regX3 two component signalling system that controls carbon source usage and mechanisms reducing damaging reactive oxygen species generated by aerobic metabolism [45]. The attenuated BCG vaccine characteristically contains a low MIRU3 tandem repeat copy number which has been suggested to be involved in the control of sensX3-regX3 expression [46]. In this study $316 \mathrm{~F}$ strains (316FNLD1978, 316FUK2001, 316FNLD2008) had low MIRU3 copy numbers whilst others, mostly originating from older culture stocks, were larger. This may represent a potential for genomic drift within recent $316 \mathrm{~F}$ lineages and could be used as a marker for the most current $316 \mathrm{~F}$
VLA, UK strain but may also be suggestive that loss of intracellular persistence in full genome complement $316 \mathrm{~F}$ strains may be associated with reduced transcriptomic signalling capacity. It will be of interest therefore in future total genome sequencing studies to compare dysfunctional SNP variations within signalling features of $316 \mathrm{~F}$ strain genomes.

\section{Conclusions}

This study has shown that significant genomic diversity exists between MAP vaccine strains and within the $316 \mathrm{~F}$ lineage. These include large deletions, duplications and changes in insertion sequence copies. These mutations were probably derived in a classical manner by selective subculture on laboratory media and in some cases have led to significant alterations of phenotype and attenuation. There were 25 MAP specific gene deletions identified of which at least one could be linked to phenotypic change that would disadvantage its persistence in the host and thus associates it with virulence. Furthermore, these MAP-specific gene deletions could provide the basis for a DIVA diagnostic for use with these vaccines. Overall, this work illustrates that MAP genome plasticity can be influenced by in vitro culture over long periods and a robust definition of vaccine strain genome lineage will be necessary in the future to guarantee consistency between studies.

\section{Methods}

\section{Strains and culture media}

MAP strains used in this work, their origins, sources and media used for propagation are described in Table 8.

\section{DNA extraction}

DNA was extracted for typing and arrays using a previously described protocol [26]. Briefly, $1 \times 10^{9}$ cells of cultures grown on liquid Middlebrook 7H9 medium for up to 12 weeks were pelleted, washed once in $1 \mathrm{x}$ PBS, then resuspended in $650 \mu \mathrm{l}$ mycobacterial lysis buffer (0.5 M EDTA - pH 8.0-, $5 \mathrm{M} \mathrm{NaCl}, 1 \mathrm{M}$ TrisHCl, $10 \%$ SDS and $8.6 \mathrm{ml} \mathrm{H}_{2} \mathrm{O}$ ). Colonies were emulsified by passing 10 times through a $25 \mathrm{G}$ needle, and treated overnight at $37^{\circ} \mathrm{C}$ with $5 \mu \mathrm{l}$ lysozyme (Stock $100 \mathrm{mg} / \mathrm{ml}$ : Sigma), $10 \mu \mathrm{l}$ proteinase K (Stock $10 \mathrm{mg} / \mathrm{ml}$ : Sigma) and $4 \mu \mathrm{l}$ lipase 
Table 8 Details of MAP strains used in this study

\begin{tabular}{|c|c|c|}
\hline Name & Origin and source & $\begin{array}{l}\text { Medium used for maintenance and } \\
\text { propagation }\end{array}$ \\
\hline $\begin{array}{l}\text { 316FNOR } 1960 \\
\text { (Vaccine strain) }\end{array}$ & $\begin{array}{l}\text { Obtained from the VLA in } 1960 \text { and used in a vaccine trial in goats in Norway } \\
\text { during the 1960s [15]. Maintained at the Norwegian Veterinary Institute, Oslo. }\end{array}$ & $\begin{array}{l}\text { Selective Dubos medium [47] supplement } \\
\text { with mycobactin }(2 \mu \mathrm{g} / \mathrm{ml}) \text { and pyruvate } \\
(4 \mathrm{mg} / \mathrm{ml})\end{array}$ \\
\hline $\begin{array}{l}\text { 316FCYP1966 } \\
\text { (Vaccine strain) }\end{array}$ & $\begin{array}{l}\text { Obtained from the VLA in } 1966 \text { as lyophilised aliquots and used to vaccinate } \\
\text { goats in Cyprus during the 1960s [18]. Strain used in this study was recovered } \\
\text { from an aliquot lyophilised on } 04 \text { January } 1966 \text { and resuscitated in } 2009 \text { with limited } \\
\text { passage since. }\end{array}$ & $7 \mathrm{H} 9^{*}$ \\
\hline $\begin{array}{l}\text { 316FNLD1978 } \\
\text { (Vaccine strain) }\end{array}$ & $\begin{array}{l}\text { Obtained from the VLA in } 1978 \text { and used as a killed vaccine [38]. } \\
\text { Maintained at the Central Veterinary Institute, Lelystad, Netherlands. }\end{array}$ & $\begin{array}{l}\text { Potato starch medium (P.Willemsen } \\
\text { personal communication) }\end{array}$ \\
\hline $\begin{array}{l}\text { 316FNEO4/81 } \\
\text { (Vaccine strain) }\end{array}$ & $\begin{array}{l}\text { Neoparasec vaccine (Merial, France) subcultures from a stock [25] assumed to be } \\
\text { derived from a } 316 \text { F Weybridge UK strain purchased in the 1980s. }\end{array}$ & $7 \mathrm{H} 9^{*}$ or $7 \mathrm{H} 11^{* *}$ \\
\hline \multicolumn{3}{|l|}{$\begin{array}{l}316 F N E O 8 / 81 \\
\text { (Vaccine strain) }\end{array}$} \\
\hline \multicolumn{3}{|l|}{$\begin{array}{l}\text { 316FNEO68451-2 } \\
\text { (Vaccine strain) }\end{array}$} \\
\hline \multicolumn{3}{|l|}{$\begin{array}{l}\text { 316FNEO69341 } \\
\text { (Vaccine strain) }\end{array}$} \\
\hline $316 v$ & $\begin{array}{l}\text { Australian strain derived from a variant labelled } 316 f \text { around } 1986 \text { [48] which itself } \\
\text { was obtained from a New Zealand source who obtained the strain in the early 1980s. } \\
\text { Maintained at the University of Sydney, Sydney, Australia. }\end{array}$ & $\begin{array}{l}\text { Mycobactin free medium but grew poorly } \\
\text { (R Whittington, personal communication) }\end{array}$ \\
\hline $\begin{array}{l}\text { 316FUK2000 } \\
\text { (Vaccine strain) }\end{array}$ & $\begin{array}{l}\text { Obtained from the VLA in } 2000 \text { and maintained at St George's Hospital Medical } \\
\text { School, London, UK, with limited passage. }\end{array}$ & Liquid Watson Reid $^{\dagger}$ \\
\hline $\begin{array}{l}\text { 316FUK2001 } \\
\text { (Vaccine strain) }\end{array}$ & $\begin{array}{l}\text { Obtained as a lyophilised stock from the VLA in } 2001 \text { and maintained at the } \\
\text { Moredun Research Institute, Scotland, UK. }\end{array}$ & $7 \mathrm{H} 11^{* *}$ \\
\hline $\begin{array}{l}\text { 316FNLD2008 } \\
\text { (Vaccine strain) }\end{array}$ & $\begin{array}{l}\text { Obtained from VLA in } 2008 \text { and maintained at the Central Veterinary Institute, } \\
\text { Lelystad, Netherlands }\end{array}$ & HEYM \\
\hline $\begin{array}{l}\text { IIUK2000 } \\
\text { (Vaccine strain) }\end{array}$ & $\begin{array}{l}\text { Obtained from the VLA in } 2000 \text { and maintained at St George's Hospital Medical } \\
\text { School, London, UK. }\end{array}$ & Liquid Watson Reid ${ }^{\dagger}[14]$ \\
\hline $\begin{array}{l}\text { IIUK2001 } \\
\text { (Vaccine strain) }\end{array}$ & $\begin{array}{l}\text { Obtained as a lyophilised stock from the VLA in } 2001 \text { and maintained at the } \\
\text { Moredun Research Institute, Scotland, UK. }\end{array}$ & $7 \mathrm{H} 11^{* *}$ \\
\hline $\begin{array}{l}\text { 2eUK2000 } \\
\text { (Vaccine strain) }\end{array}$ & $\begin{array}{l}\text { Obtained from the VLA in } 2000 \text { and maintained at St George's Hospital Medical } \\
\text { School, London, UK. }\end{array}$ & Liquid Watson Reid 'A' Block ${ }^{\dagger+}$ medium \\
\hline $\begin{array}{l}\text { 2eUK2001 } \\
\text { (Vaccine strain) }\end{array}$ & $\begin{array}{l}\text { Obtained as a lyophilised stock from the VLA in } 2001 \text { and maintained at the } \\
\text { Moredun Research Institute, Scotland, UK. }\end{array}$ & $7 \mathrm{H} 11^{* *}$ \\
\hline $\begin{array}{l}\text { MAPK10 (Wild } \\
\text { type strain) }\end{array}$ & $\begin{array}{l}\text { Purchased from ATCC: BAA-968. Sequenced reference strain isolated from a } \\
\text { cow in } 1990 .\end{array}$ & $7 \mathrm{H} 9^{*}$ or $7 \mathrm{H} 11^{* *}$ \\
\hline $\begin{array}{l}\text { CAM87 (Wild } \\
\text { type strain) }\end{array}$ & $\begin{array}{l}\text { MAP Type III strain isolated from a goat in } 2005 \text { [26] and maintained at } \\
\text { the Universidad Complutense de Madrid, Madrid, Spain. }\end{array}$ & $7 \mathrm{H} 9^{*}$ \\
\hline $\begin{array}{l}\text { JD87/107 (Wild } \\
\text { type strain) }\end{array}$ & $\begin{array}{l}\text { Isolated from a deer in } 1987 \text { and maintained at the Moredun Research Institute, } \\
\text { Scotland, UK. }\end{array}$ & $7 \mathrm{H} 11^{* *}$ \\
\hline
\end{tabular}

"7H9: Middlebrooks 7H9 (Becton Dickinson, UK) supplemented with 2 mg/L Mycobactin J (Allied Monitor, USA), 0.5\% glycerol, 10\% oleic acid-albumin-dextrosecatalase (OADC) enrichment medium (Difco, UK), $25 \mathrm{mg} / \mathrm{L}$ amphotericin B, $35 \mathrm{mg} / \mathrm{L}$ naladixic acid and $35 \mathrm{mg} / \mathrm{L}$ vancomycin.

${ }^{* *} 7 \mathrm{H} 11$ : Middlebrooks $7 \mathrm{H} 11$ (Becton Dickinson, UK) agar supplemented with $2 \mathrm{mg} / \mathrm{L}$ Mycobactin J (Allied Monitor, USA), 2.5\% glycerol (v/v), 10\% OADC (v/v) enrichment medium (Difco, UK), 20\% (v/v) new born calf serum, $0.3 \mathrm{~g} / \mathrm{L}$ asparagine, Mycobacteria Selectatabs (10 mg/L amphotericin B, 200,000 units/L polymixin $\mathrm{B}, 100 \mathrm{mg} / \mathrm{L}$ ticarcillin and $10 \mathrm{mg} / \mathrm{L}$ trimethoprim [MAST Laboratories Ltd, UK]).

${ }^{+}$Liquid Watson Reid: Asparagine $5 \mathrm{~g} / \mathrm{l}$, Potassium dihydrogen phosphate $2 \mathrm{~g} / \mathrm{l}$, Magnesium suphate $1 \mathrm{~g} / \mathrm{l}$, Tri-ammonium citrate $2 \mathrm{~g} / \mathrm{l}$, Sodium chloride $2 \mathrm{~g} / \mathrm{l}, \mathrm{D}(+)$ Glucose $10 \mathrm{~g} / \mathrm{l}$, Glycerol $48 \mathrm{ml} / \mathrm{l}$, Ammonium iron (III) citrate brown $0.075 \mathrm{~g} / \mathrm{l}, 1.33 \mathrm{mls}$ of Supplement A: $2 \mathrm{~g} / \mathrm{l}$ Zinc sulphate, $2 \mathrm{~g} / \mathrm{l}$ Copper sulphate, $1 \mathrm{~g} / \mathrm{l}$ Cobalt nitrate, $1.33 \mathrm{mls}$ of Supplement B; $50 \mathrm{~g} / \mathrm{l}$ Calcium chloride.

${ }^{+t}$ Liquid Watson Reid 'A' Block: as Watson Reid medium but without supplements A and B.

(Stock $121 \mathrm{mg} / \mathrm{ml} \mathrm{Sigma).} \mathrm{Samples} \mathrm{were} \mathrm{ribolysed} \mathrm{(Lysing}$ Matrix B; Qbiogene) at 6,500 rpm for $50 \mathrm{sec}$, iced for $10 \mathrm{~min}$ then $400 \mu \mathrm{l}$ of lysate added to $400 \mu \mathrm{l}$ of Qiagen DNAeasy AL lysis buffer, mixed and applied to a DNAeasy column. $200 \mu \mathrm{l}$ of $100 \%$ ethanol was added and columns centrifuged at 8,000 rpm for $1 \mathrm{~min}$, washed in $500 \mu \mathrm{l}$
Qiagen Lysis buffer 1 and 2, then eluted in $90 \mu \mathrm{l}$ DNA/ RNAse free $\mathrm{H}_{2} \mathrm{O}$ overnight on the column at $4^{\circ} \mathrm{C}$.

\section{MIRU3 typing and IS900 locus PCR}

Five microlitres of MAP DNA extracted from test strains was amplified for MIRU [49] or IS900 [40] as previously 
described using $2 \mu \mathrm{M}$ primers MIRU3.F\& MIRU3.R spanning the MAP3982-MAP3983 locus or with IS900 locus specific primers designed to amplify across the complete IS900 insertion from immediately adjacent loci (Table 6). All PCR reactions used 1x Expand reaction buffer containing $1.5 \mathrm{mM} \mathrm{MgCl}_{2}, 10 \%$ DMSO, $100 \mu \mathrm{M}$ dNTP and 1 unit Expand High Fidelity Taq polymerase (Roche). Cycling conditions were: $95^{\circ} \mathrm{C}: 3$ min: 1 cycle; $94^{\circ} \mathrm{C}: 30 \mathrm{sec}$ : $60^{\circ} \mathrm{C}: 30 \mathrm{sec}: 72^{\circ} \mathrm{C}: 1 \mathrm{~min}: 35$ cycles; $72^{\circ} \mathrm{C}: 5 \mathrm{~min}: 1$ cycle. Confirmation of amplicon product size in bp was made on $1.8 \%$ agarose gels.

\section{MAPAC microarray hybridisation and analysis}

DNA from the test strain and reference MAP K-10 strain were fluorescently labelled and hybridised to the microarray using protocols described previously [50]. Briefly, $1 \mu \mathrm{g}$ of DNA was labelled by random priming with Klenow polymerase to incorporate either $\mathrm{Cy} 3$ or $\mathrm{Cy} 5$ dCTP (GE Healthcare) for the test strain and reference strain respectively. Equal amounts of the Cy3 and Cy5 labelled samples were co-purified through a Qiagen MinElute column (Qiagen), mixed with a formamidebased hybridisation solution (1×MES, $1 \mathrm{M} \mathrm{NaCl}, 20 \%$ formamide, $0.02 \mathrm{M}$ EDTA, 1\% Triton) and denatured at $95^{\circ} \mathrm{C}$ for $2 \mathrm{~min}$. The labelled sample was loaded on to a prehybridised $(3.5 \times \mathrm{SSC}, 0.1 \% \mathrm{SDS}, 10 \mathrm{mg} / \mathrm{ml} \mathrm{BSA})$ microarray under two $22 \times 22 \mathrm{~mm}$ LifterSlips (Erie Scientific), sealed in a humidified hybridisation cassette (Corning) and hybridised overnight by immersion in a waterbath at $55^{\circ} \mathrm{C}$ for $16-20 \mathrm{~h}$. Slides were washed once in $400 \mathrm{ml}$ $1 \times \mathrm{SSC} 0.06 \% \mathrm{SDS}$ at $55^{\circ} \mathrm{C}$ for $2 \mathrm{~min}$ and twice in $400 \mathrm{ml}$ $0.06 \times \mathrm{SSC}$ for $2 \mathrm{~min}$. Microarrays were scanned using an Affymetrix 428 scanner, and signal intensity data were extracted using BlueFuse for Microarrays v3.5 (BlueGnome). The intensity data was further postprocessed using BlueFuse to exclude both controls and low confidence data $(\mathrm{p}<0.1)$ prior to normalisation by $2 \mathrm{D}$ Lowess (window size $=20$ ) and median centring. Further analysis of the normalised data was undertaken using BlueFuse, GeneSpring 7.3.1 (Agilent Technologies) and Eisen Cluster [51]. Fully annotated microarray data has been deposited in B $\mu \mathrm{G} @ S b a s e$ (accession number: EBUGS-264; http://bugs.sgul.ac.uk/E-BUGS-264) and also ArrayExpress (accession number: E-BUGS-264).

\section{qPCR}

Relative copy number of amplicons were generated from IS900, MAP0101 and MAP0103 primer sets and compared against absolute amplicon numbers obtained from a MAP2114c primer set (Table 6). Reactions comprised $2 \mu$ l genomic DNA sample, $12.5 \mu$ l Power SYBR green mastermix (Applied Biosystems, Cat 4368706), 2
pMoles appropriate primer pairs, made to $25 \mu \mathrm{l}$ with RNAse free $\mathrm{H} 2 \mathrm{O}$. PCR cycling used $95^{\circ} \mathrm{C}: 15 \mathrm{mins}$ ( 1 cycle); at $95^{\circ} \mathrm{C}$ :30secs, $58^{\circ} \mathrm{C}: 1 \mathrm{~min}, 72^{\circ} \mathrm{C}: 1 \mathrm{~min}$ (40 cycles) with data collection at $76^{\circ} \mathrm{C}$ (10secs) using a CFX96 qPCR cycler (BioRad, UK). Sample copy numbers were estimated from an averaged value of three qPCR's on each sample using a dilution curve of a control stock total genomic DNA MAP $\mathrm{K}-10$ preparation serially diluted 10 fold to contain between $1 \times 10^{2}-10^{6}$ genome copies.

\section{Tellurite MIC}

Cultures of MAP strains were grown in conventional liquid media to exponential phase for 6 weeks then adjusted to $10^{4} \mathrm{cfu} / \mathrm{ml}$ using OD550. Aliquots $(10 \mu \mathrm{l})$ were inoculated onto solid RAF medium in petri dishes containing serial dilution of potassium tellurite to final concentrations of $512,256,128,64,32,16,8,4$ or $0 \mu \mathrm{g} / \mathrm{ml}$ and incubated at $37^{\circ} \mathrm{C}$. MIC's were taken as the least tellurite concentration able to inhibit $>90 \%$ growth, seen as black colonies, after 6 weeks of growth and 12 weeks growth for strain IIUK2000 which was slower to grow in vitro.

\section{Assessment of virulence using a mouse model}

The virulence of vaccine strains 316FUK2001, IIUK2001 and 2eUK2001 was compared with wild type strain JD87/ 107 in a mouse model. 316FUK2001, IIUK2001 and 2eUK2001 were selected to represent the three different vaccine strains that have been used for control of JD over the years. JD87/107 was selected as the control strain as this was the virulent wild type strain that was used previously in our laboratory to optimise the mouse model and PBS was used as a negative control. C57BL/6 mice of approximately five weeks old and between 20 and $25 \mathrm{~g}$ in weight were purchased from Harlan UK, Shaws Farm, Blackthorn, Bicester, Oxon OX25 1TP. The mice were individually weighed and randomly assigned to five groups of 30. One negative control group was inoculated with $0.1 \mathrm{ml}$ of sterile PBS. The remaining groups were inoculated intraperitoneally with 1.1 to $1.4 \times 10^{8}$ organisms in $0.1 \mathrm{ml}$ PBS of one of the MAP strains 2eUK2001, IIUK2001, 316FUK2001 and JD87/107. The inocula were prepared as previously described [52] and enumerated by performing a microscopic count. Ten mice from each group were killed at 4, 8 and 12 weeks post inoculation by exposure to a mixture of carbon dioxide and halothane gas followed by cervical dislocation. Each mouse was weighed and the body weight recorded. The spleens and livers were removed aseptically and weighed. The respective weights were expressed as a percentage of body weight for each mouse. Approximately $0.1 \mathrm{~g}$ of liver was removed for 
bacteriological culture and the remaining tissue fixed in $10 \%$ formal saline for histopathological examination.

Hepatic bacterial load was assessed by using serial dilutions of a 10\% (wt/wt) liver homogenate in PBS. $0.1 \mathrm{ml}$ of each dilution was inoculated onto 7H11 agar with supplements as detailed in Table 8 and incubated at $37^{\circ} \mathrm{C}$ for up to 16 weeks. Colony counts for each animal replicate were estimated by fitting a generalised linear model to the dilution assay counts assuming an overdispersed Poisson response and a logarithmic link function while fitting the logarithm of the dilution as an offset variable to the fixed mean. It was assumed that observations greater than 200 CFU per field could not be quantified accurately, and such observations were included in the likelihood as taking unknown values greater than this threshold.

The fixed liver samples were given a random code to assure that the samples were assessed blind by the pathologist. The samples were processed to paraffin wax and $5 \mu \mathrm{m}$ sections prepared. The sections were stained with haematoxylin and eosin (H\&E) and Ziehl-Neelsen (ZN) method . Using an Olympus BX50 microscope, the number of leucocyte clusters was counted in approximately 100 fields at $\times 200$ magnification from each individual animal using an eyepiece graticule (Pyser-SGI Ltd, NE35-24 mm) and the counts normalised to 1 field. A leucocyte cluster was defined as an accumulation of more than 10 mononuclear leucocytes. The infectious load of each animal was assessed by counting leucocyte clusters containing AFB. Because the detection of AFB requires higher magnification (x400-600), the number of leucocyte clusters with AFB was assessed separately. Depending on the original leucocyte cluster density, up to sixty leucocyte clusters were assessed in detail and the proportion of leucocyte clusters containing AFB determined. Based on the leucocyte cluster counts and the proportion of leucocyte clusters containing AFB, the infectious load was expressed as the mean number of AFB positive leucocyte clusters per field.

All data were analysed by fitting a linear mixed model to either the data as specified above or to the ranks of these data, with this choice being made on the basis of the normality of residuals in the model fitted to the original data. The mixed model approach was preferred to traditional ANOVA to better allow for replicates missing at random from the sample. Strain and Week and interactions were fitted as fixed effects, animal replicate as a random residual effect. Statistical analysis was carried out using Genstat version 14 and using user-defined macros in Excel 2007. All statistical analysis and derivations of $P$ values are provided in Additional File 2).

\section{Ethical considerations}

All experimental procedures and management protocols were examined and approved by the Moredun Research
Institute Experiments and Ethics Committee and conducted within the framework of the UK 'Animals (Scientific Procedures) Act 1986' administered by the Home Office of the UK government.

\section{Additional files}

Additional file 1: PCR amplification for vGl-19, vGl-20 and vGI-21 in
316FUK2001, 2eUK2001 and IIUK2001 strains. Gels of specific PCR
amplicons.
Additional file 2: Mouse Model Data File. Tables and statistical
analyses of virulence experiments in mice.

Competing interests

The authors declare that they have no competing interests.

\section{Authors' contributions}

TB conceived of the study, carried out the molecular studies and data analyses and drafted the manuscript. AS contributed to conception and design and performed the histopathological examinations and data analysis of the mouse studies. JMS conceived of the study, participated in design, execution and analysis of the mouse studies. MG participated in the mouse studies. IJM and JS participated in the design, carried out statistical analyses of data from the mouse studies and contributed statistical text to the final manuscript. RL carried out the molecular studies and data analyses. KS conceived of the study, participated in the design, coordination, execution and analysis of the mouse studies and help draft the final manuscript. All authors read and approved the final manuscript.

\section{Acknowledgements}

The authors would like to thank the Animal Health Veterinary Laboratories Agency and the following people for provision of strains for this study: D. Bakker (Central Veterinary Institute, Lelystad, The Netherlands) for 316FNLD2008 and 316FNLD1978; R. W. Crowther (UNDP, Cyprus) for 316FCYP1966, I. Olsen (Norwegian Veterinary Institute, Norway) for 316FNOR1960; and F. Biet (INRA, France) for the $316 \mathrm{~F}$ Neoparasec subcultures. This work was funded by EU Project ParaTBTools FP6-2004-FOOD-3B-023106 and the Scottish Government Rural and Environment Science and Analytical Services Division.

\section{Author details}

${ }^{1}$ St. George's University of London Medical School, London SW17 ORE, UK. ${ }^{2}$ AHVLA Lasswade, Bush Loan, Penicuik, Midlothian EH26 OPZ, UK. ${ }^{3}$ Moredun Research Institute, Bush Loan, Penicuik, Midlothian EH26 OPZ, UK.

${ }^{4}$ Biomathematics \& Statistics Scotland, James Clerk Maxwell Building, The King's Buildings, Mayfield Road, Edinburgh EH9 3JZ, UK. ${ }^{5}$ Present address: Charter Veterinary Surgeons, 51 Congleton Road, Stoke On Trent ST8 6EF, UK.

Received: 19 July 2012 Accepted: 11 January 2013

Published: 22 January 2013

\section{References}

1. Hutchings MR, Stevenson K, Greig A, Davidson RS, Marion G, Judge J: Infection of Non-ruminant Wildlife by Mycobacterium avium subsp. paratuberculosis. In Paratuberculosis; Organism, Disease, Control. Edited by Behr MA, Collins DM. Wallingford: CAB International; 2010:188-200.

2. Raizman EA, Fetrow JP, Wells SJ: Loss of income from cows shedding mycobacterium avium subspecies paratuberculosis prior to calving compared with cows not shedding the organism on two Minnesota dairy farms. J Dairy Sci 2009, 92:4929-4936.

3. Behr MA, Kapur V: The evidence for mycobacterium paratuberculosis in Crohn's disease. Curr Opin Gastroenterol 2008, 24:17-21.

4. van Schaik G, Kalis CH, Benedictus G, Dijkhuizen AA, Huirne RB: Cost-benefit analysis of vaccination against paratuberculosis in dairy cattle. Vet Rec 1996, 139:624-627.

5. Muskens J, Elbers AR, van Weering HJ, Noordhuizen JP: Herd management practices associated with paratuberculosis seroprevalence in Dutch dairy herds. J Vet Med B Infect Dis Vet Public Health 2003, 50:372-377. 
6. Kudahl AB, Sorensen JT, Nielsen SS, Ostergaard S: Simulated economic effects of improving the sensitivity of a diagnostic test in paratuberculosis control. Prev Vet Med 2007, 78:118-129.

7. Hines ME, Stiver S, Giri D, Whittington L, Watson C, Johnson J, et al: Efficacy of spheroplastic and cell-wall competent vaccines for Mycobacterium avium subsp. paratuberculosis in experimentally-challenged baby goats. Vet Microbiol 2007, 120:261-283.

8. Emery DL, Whittington RJ: An evaluation of mycophage therapy, chemotherapy and vaccination for control of Mycobacterium avium subsp. paratuberculosis infection. Vet Microbio/ 2004, 104:143-155.

9. Juste RA, Alonso-Hearn M, Molina E, Geijo M, Vazquez P, Sevilla IA, et al: Significant reduction in bacterial shedding and improvement in milk production in dairy farms after the use of a new inactivated paratuberculosis vaccine in a field trial. BMC Res Notes 2009, 2:233.

10. Pickup RW, Rhodes G, Arnott S, Sidi-Boumedine K, Bull TJ, Weightman A, et al: Mycobacterium avium subsp. paratuberculosis in the catchment area and water of the River Taff in South Wales, United Kingdom, and its potential relationship to clustering of Crohn's disease cases in the city of Cardiff. Appl Environ Microbiol 2005, 71:2130-2139.

11. Rosseels $V$, Huygen K: Vaccination against paratuberculosis. Expert ReV Vaccines 2008, 7:817-832

12. Singh SV, Singh PK, Singh AV, Sohal JS, Gupta VK, Vihan VS: Comparative efficacy of an indigenous 'inactivated vaccine' using highly pathogenic field strain of Mycobacterium avium subspecies paratuberculosis 'Bison type' with a commercial vaccine for the control of Capriparatuberculosis in India. Vaccine 2007, 25:7102-7110.

13. Kozak R, Behr MA: Divergence of immunologic and protective responses of different BCG strains in a murine model. Vaccine 2011, 29:1519-1526.

14. Doyle TM: Strains of Mycobacterium johnei used for the preparation of vaccine. State Veterinary Journal 1964, 19-20:154-155.

15. Saxegaard F, Fodstad FH: Control of paratuberculosis (Johne's disease) in goats by vaccination. Vet Rec 1985, 116:439-441.

16. Sigurdsson B, Tryggvadottir AG: Immunization with heat-killed Mycobacterium paratuberculosis in mineral oil. J Bacteriol 1950, 59:541-543.

17. Wilesmith JW: Johne's disease: a retrospective study of vaccinated herds in Great Britain. Br Vet J 1982, 138:321-331.

18. Crowther RW, Polydorou K, Nitti S, Phyrilla A: Johne's disease in sheep in Cyprus. Vet Rec 1976, 98:463.

19. Kormendy $B$ : The effect of vaccination on the prevalence of paratuberculosis in large dairy herds. Vet Microbiol 1994, 41:117-125.

20. Klawonn W, Cussler K, Drager KG, Gyra H, Kohler H, Zimmer K, et al: [The importance of allergic skin test with Johnin, antibody ELISA, cultural fecal test as well as vaccination for the sanitation of three chronically paratuberculosis-infected dairy herds in Rhineland-Palatinate]. Dtsch Tierarztl Wochenschr 2002, 109:510-516.

21. Molina JM, Anguiano A, Ferrer O: Study on immune response of goats vaccinated with a live strain of Mycobacterium paratuberculosis. Comp Immunol Microbiol Infect Dis 1996, 19:9-15.

22. Begg DJ, Griffin JF: Vaccination of sheep against M. paratuberculosis: immune parameters and protective efficacy. Vaccine 2005, 23:4999-5008.

23. Reddacliff $L$, Eppleston J, Windsor $P$, Whittington R, Jones S: Efficacy of a killed vaccine for the control of paratuberculosis in Australian sheep flocks. Vet Microbiol 2006, 115:77-90.

24. Thorel MF: Review of the occurrence of mycobactin dependence among mycobacteria species. Ann Rech Vet 1984, 15:405-409.

25. Thibault VC, Grayon M, Boschiroli ML, Hubbans C, Overduin P, Stevenson K, et al: New variable-number tandem-repeat markers for typing Mycobacterium avium subsp. paratuberculosis and $M$. avium strains: comparison with IS900 and IS1245 restriction fragment length polymorphism typing. J Clin Microbiol 2007, 45:2404-2410.

26. Castellanos E, Aranaz A, Gould KA, Linedale R, Stevenson K, Alvarez J, et al: Discovery of stable and variable differences in the Mycobacterium avium subsp. paratuberculosis type I, II, and III genomes by pan-genome microarray analysis. Appl Environ Microbiol 2009, 75:676-686.

27. Taylor DE: Bacterial tellurite resistance. Trends Microbio/ 1999, 7:111-115.

28. Chasteen TG, Fuentes DE, Tantalean JC, Vasquez CC: Tellurite: history, oxidative stress, and molecular mechanisms of resistance. FEMS Microbiol Rev 2009, 33:820-832
29. Watkins C, Schock A, May L, Denham S, Sales J, Welch L, et al: Assessing virulence of vaccine strains of Mycobacterium avium subspecies paratuberculosis in a calf model. Vet Microbiol 2010, 146:63-69.

30. Stratmann J, Strommenger B, Goethe R, Dohmann K, Gerlach GF, Stevenson $K$, et al: A 38-kilobase pathogenicity island specific for Mycobacterium avium subsp. paratuberculosis encodes cell surface proteins expressed in the host. Infect Immun 2004, 72:1265-1274.

31. Paustian ML, Amonsin A, Kapur V, Bannantine JP: Characterization of novel coding sequences specific to mycobacterium avium subsp. Paratuberculosis: implications for diagnosis of Johne's disease. J Clin Microbiol 2004, 42:2675-2681

32. Beste DJ, Bonde B, Hawkins N, Ward JL, Beale MH, Noack S, et al: (1)(3)C metabolic flux analysis identifies an unusual route for pyruvate dissimilation in mycobacteria which requires isocitrate lyase and carbon dioxide fixation. PLoS Pathog 2011, 7:e1002091.

33. Wayne LG, Lin KY: Glyoxylate metabolism and adaptation of Mycobacterium tuberculosis to survival under anaerobic conditions. Infect Immun 1982, 37:1042-1049.

34. McKinney JD, BK Hz, Munoz-Elias EJ, Miczak A, Chen B, Chan WT, et al: Persistence of Mycobacterium tuberculosis in macrophages and mice requires the glyoxylate shunt enzyme isocitrate lyase. Nature 2000, 406:735738 .

35. Hasvold HJ, Valheim M, Berntsen G, Storset AK: In vitro responses to purified protein derivate of caprine T lymphocytes following vaccination with live strains of Mycobacterium avium subsp paratuberculosis. Vet Immunol Immunopathol 2002, 90:79-89.

36. Cooper WC: Tellurium. New York: Van Nostrand Reinhold; 1971.

37. Calderon IL, Arenas FA, Perez JM, Fuentes DE, Araya MA, Saavedra CP, et al: Catalases are NAD(P)H-dependent tellurite reductases. PLoS One 2006, 1:e70.

38. Muskens J, van ZF, Eger A, Bakker D: Evaluation of the long-term immune response in cattle after vaccination against paratuberculosis in two Dutch dairy herds. Vet Microbiol 2002, 86:269-278.

39. Wynne JW, Bull TJ, Seemann T, Bulach DM, Wagner J, Kirkwood CD, et al: Exploring the zoonotic potential of Mycobacterium avium subspecies paratuberculosis through comparative genomics. PLoS One 2011, 6:e22171.

40. Bull TJ, Hermon-Taylor J, Pavlik I, El-Zaatari F, Tizard M: Characterization of IS900 loci in Mycobacterium avium subsp. paratuberculosis and development of multiplex PCR typing. Microbiology 2000, 146(Pt 9):2185-2197.

41. Eamens GJ, Whittington RJ, Marsh IB, Turner MJ, Saunders V, Kemsley PD, et al: Comparative sensitivity of various faecal culture methods and ELISA in dairy cattle herds with endemic Johne's disease. Vet Microbiol 2000, 77:357-367

42. Collins DM, Gabric DM, de Lisle GW: Identification of two groups of Mycobacterium paratuberculosis strains by restriction endonuclease analysis and DNA hybridization. J Clin Microbiol 1990, 28:1591-1596.

43. Mahillon J, Chandler M: Insertion sequences. Microbiol Mol Biol Rev 1998, 62:725-774.

44. Klanicova B, Slana I, Vondruskova H, Kaevska M, Pavlik I: Real-time quantitative PCR detection of Mycobacterium avium subspecies in meat products. J Food Prot 2011, 74:636-640.

45. Roberts G, Vadrevu IS, Madiraju MV, Parish T: Control of CydB and GltA1 expression by the SenX3 RegX3 two component regulatory system of Mycobacterium tuberculosis. PLOS One 2011, 6:e21090.

46. Magdalena J, Supply P, Locht C: Specific differentiation between Mycobacterium bovis BCG and virulent strains of the Mycobacterium tuberculosis complex. J Clin Microbiol 1998, 36:2471-2476.

47. Saxegaard F: Isolation of Mycobacterium paratuberculosis from intestinal mesenteric lymph nodes of goats by use of selective Dubos medium. J Clin Microbiol 1985, 22:312-313.

48. Cousins DV, Gabric DM, deLisle GW: Identification of two groups of Mycobacterium paratuberculosis strains by restriction endonuclease analysis and DNA hybridisation. J Clin Microbiol 1990, 28:1591-1596.

49. Bull TJ, Sidi-Boumedine K, McMinn EJ, Stevenson K, Pickup R, Hermon-Taylor $\mathrm{J}$ : Mycobacterial interspersed repetitive units (MIRU) differentiate Mycobacterium avium subspecies paratuberculosis from other species of the Mycobacterium avium complex. Mol Cell Probes 2003, 17:157-164. 
50. Dorrell N, Mangan JA, Laing KG, Hinds J, Linton D, Al-Ghusein $\mathrm{H}$, et al: Whole genome comparison of Campylobacter jejuni human isolates using a low-cost microarray reveals extensive genetic diversity. Genome Res 2001, 11:1706-1715.

51. Eisen MB, Spellman PT, Brown PO, Botstein D: Cluster analysis and display of genome-wide expression patterns. Proc Natl Acad Sci USA 1998, 95:14863-14868.

52. Beard PM, Stevenson K, Pirie A, Rudge K, Buxton D, Rhind SM, et al: Experimental paratuberculosis in calves following inoculation with a rabbit isolate of Mycobacterium avium subsp. paratuberculosis. J Clin Microbiol 2001, 39:3080-3084.

doi:10.1186/1471-2180-13-11

Cite this article as: Bull et al:: Genomic variations associated with attenuation in Mycobacterium avium subsp. paratuberculosis vaccine strains. BMC Microbiology 2013 13:11.

\section{Submit your next manuscript to BioMed Central and take full advantage of:}

- Convenient online submission

- Thorough peer review

- No space constraints or color figure charges

- Immediate publication on acceptance

- Inclusion in PubMed, CAS, Scopus and Google Scholar

- Research which is freely available for redistribution 